\title{
8
}
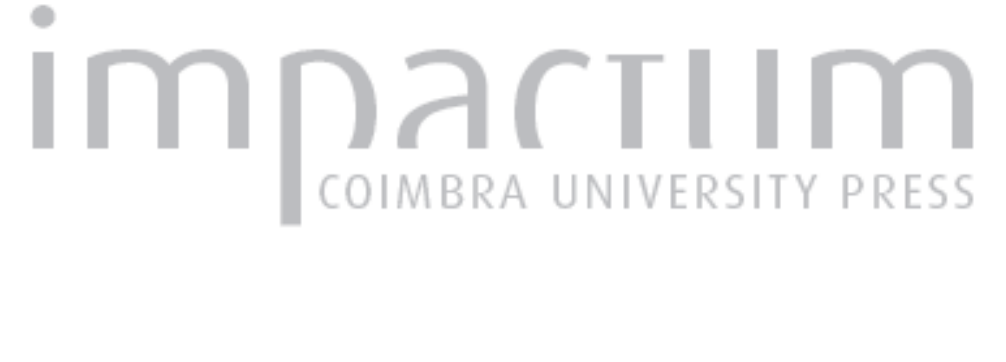

\section{Apontamentos de literatura fantástica nas Origines de Catão}

Autor(es): $\quad$ Ferreira, Paulo Sérgio Margarido

Publicado por: Imprensa da Universidade de Coimbra

URL persistente:

URl:http://hdl.handle.net/10316.2/43369

DOI: DOI:https://doi.org/10.14195/2183-7260_62_3

Accessed : $\quad$ 26-Apr-2023 11:01:16

A navegação consulta e descarregamento dos títulos inseridos nas Bibliotecas Digitais UC Digitalis, UC Pombalina e UC Impactum, pressupõem a aceitação plena e sem reservas dos Termos e Condições de Uso destas Bibliotecas Digitais, disponíveis em https://digitalis.uc.pt/pt-pt/termos.

Conforme exposto nos referidos Termos e Condições de Uso, o descarregamento de títulos de acesso restrito requer uma licença válida de autorização devendo o utilizador aceder ao(s) documento(s) a partir de um endereço de IP da instituição detentora da supramencionada licença.

Ao utilizador é apenas permitido o descarregamento para uso pessoal, pelo que o emprego do(s) título(s) descarregado(s) para outro fim, designadamente comercial, carece de autorização do respetivo autor ou editor da obra.

Na medida em que todas as obras da UC Digitalis se encontram protegidas pelo Código do Direito de Autor e Direitos Conexos e demais legislação aplicável, toda a cópia, parcial ou total, deste documento, nos casos em que é legalmente admitida, deverá conter ou fazer-se acompanhar por este aviso.

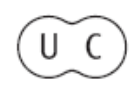


COIMBRA • 2017
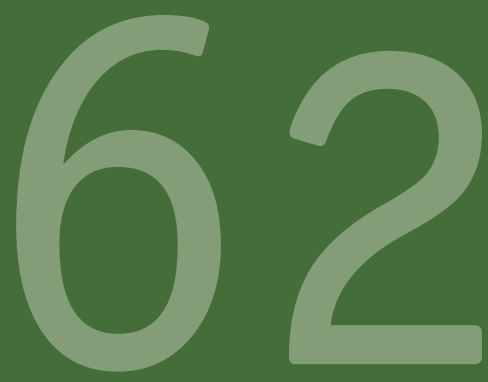

BOLETIM DE

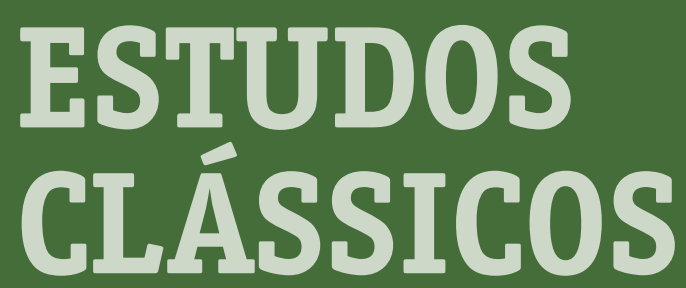

\author{
ASSOCIAÇÃO \\ PORTUGUESA \\ DE ESTUDOS \\ CLÁSSICOS \\ INSTITUTO \\ DE ESTUDOS \\ CLÁSSICOS
}




\title{
APONTAMENTOS DE LITERATURA FANTÁSTICA NAS ORIGINES DE CATÃ $0^{1}$
}

\section{NOTES OF FANTASTIC LITERATURE IN CATO'S ORIGINES}

\author{
PAULO SÉRGIO MARGARIDO FERREIRA \\ CECH - UNIVERSIDADE DE COIMBRA \\ paulusergius@yahoo.com \\ ORCID.0RG/0000-0003-4244-5625
}

ARTIGO RECEBIDO A 31-03-2017 E APROVADO A 05-07-2017

Sumário: Este estudo faz uma breve apresentação das Origines de Catão; procura, com base em Tzvetan Todorov, distinguir do fantástico o maravilhoso e o estranho; considera a origem rural e etnográfica do fantástico; reflete sobre a relação entre a verosimilhança e o fantástico; e equaciona o modo como o leitor antigo e o moderno interpretam os passos catonianos de natureza fantástica, maravilhosa ou estranha.

Palavras-chave: Catão; Origines; Tzvetan Todorov; fantástico; maravilhoso; estranho; verosimilhança.

Abstract: This study gives a brief presentation of Cato's Origines; seeks, on the basis of Tzvetan Todorov, to distinguish from the fantastic the marvellous and the uncanny genre; considers the rural and ethnographic origin of the fantastic; reflects on the relationship between

1 Este estudo procura homenagear de forma singela Tzvetan Todorov, recentemente falecido. 
verisimilitude and fantastic; and analyses the way the ancient and modern reader interpret the Catonian passages of fantastic, marvellous, or uncanny nature.

Keywords: Cato; Origines; Tzvetan Todorov; fantastic; marvellous; uncanny; verisimilitude.

Marco Pórcio Catão [Túsculo (próximo da atual Frascati), 234 - Roma, 149] escreveu, entre uma data anterior a 170 ou entre o referido ano e 149 a.C., as Origines. O título, para Chassignet, é uma originalidade, pois, ao contrário do que muitos pensam, não traduz necessariamente forma

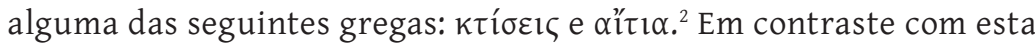
perspetiva, sustenta Albrecht: "The title Origines corresponds to the

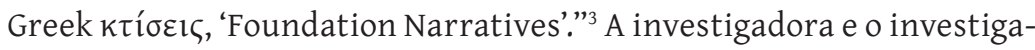
dor realçam o conhecimento do grego por parte de Catão, a presença da $k \tau i ́$ бıৎ nas narrativas fundacionais de Origines 2 e 3, e admitem a

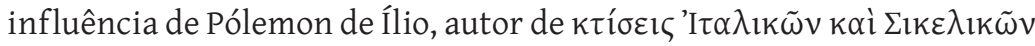
$\pi o ́ \lambda \varepsilon \omega v$, e de Timeu de Tauroménio, que escreveu uma obra cujos "cinq premiers livres [....] étaient en effet une $\pi \rho \circ \kappa \alpha \tau \alpha \sigma \kappa \varepsilon \cup \eta ́$ consacrée aux

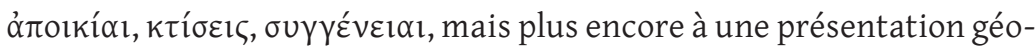
graphique et ethnographique de tout l'Occident connu et non grec."

Das Origines, compostas por sete livros, restam apenas fragmentos, pelo que a reflexão que agora se inicia se baseará sobretudo na seleção e organização que deles fez Martine Chassignet (Caton, Les Origines

2 Chassignet 1986: XIII.

3 Albrecht 1997: 396.

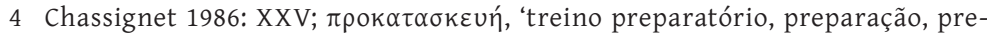

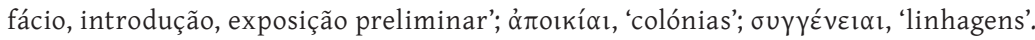
Albrecht fala no prazer que em Catão deve ter suscitado a toada moralista com que Timeu de Tauroménio criticou a decadência dos Sibaritas, dos habitantes de Crotona, dos Etruscos e dos Agrigentinos. A investigadora (1986: XXV) ainda alude à influência

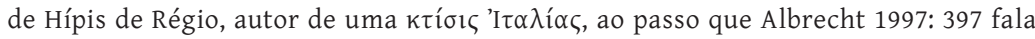
da influência de Cálias de Siracusa, de Lico de Régio e, no caso concreto da data da fundação de Roma, de Eratóstenes. 
(fragments), Paris, Les Belles Lettres, 1986, 2ème tirage: 2002). Entre as fontes antigas utilizadas na reconstituição do texto, contam-se Cícero, Dionísio de Halicarnasso, Veleio Patérculo, Plínio Naturalista, Plutarco, Aulo Gélio, Macróbio e Sérvio.

Cornélio Nepos, Cato 3. 3-4, e Festo, p. 198 Lindsay, cuidam que o título, Origines, abrange a totalidade da obra, mas, como na Antiguidade já se reconhecia, é mais ajustado aos três primeiros livros, que teriam sido escritos até 168 ou pouco depois. No primeiro deles sustenta Catão, na esteira de Antíoco de Siracusa, que o topónimo "Itália" provém do herói Ítalo (frg. 1. 3 Ch.), e considera a história da península desde a chegada dos Aborígenes, provenientes da Acaia, muitas gerações antes da Guerra de Troia [frg. 1. 4 Ch. = 1. 4 J(ordan) =6 P(eter); ...XVII a.C.], finais do séc. XVIII ou princípios do XVII a.C.), passando pela miscigenação com os Troianos e consequente formação dos Latinos (frg. 1. 6 Ch. = 1. $5 \mathrm{~J}=5 \mathrm{P}$ ), pela morte de Ascânio sem descendência, pela subida de Sílvio, filho de Lavínia e Eneias, ao trono e pela adoção do nome de Ascânio (frg. 1.11 Ch. = 11 P), pela decapitação de Amúlio por Rómulo, Remo e Numitor (frg. 1.16 Ch. = 1.15 J = 15 P), pela fundação da cidade de Roma por Rómulo, que se passou a chamar Quirino (frgs. 1. 18-19 Ch. = 1. 18-19 J = 19 P), pelas guerras entre Romanos e Sabinos (frg. 26 Ch. $=1.24 \mathrm{~J} \mathrm{=} 25 \mathrm{P}$ ), até ao final da monarquia. Os fragmentos subsistentes do segundo e terceiro livros tratam a distribuição por Itália, as características e costumes de diversos povos primitivos, ${ }^{5}$ bem como os mitos fundacionais de santuários e de cidades italianas. ${ }^{6}$

5 Lígures, frg. 2. 1 Ch. = 2. $1 \mathrm{~J}=31 \mathrm{P}$; Lepôncios e Salassos, frg. $2.7 \mathrm{Ch} .=2.6 \mathrm{~J} \mathrm{=} 37$ P; Oromóbios e Bergomates, frg. 2. 10 Ch. = 2. 4 J = 40 P; Eugâneos, frg. 2.11 Ch. = 2. 5 $\mathrm{J}=41 \mathrm{P}$; Vénetos e Cenomanos frg. $2.12 \mathrm{Ch} .=2.9 \mathrm{~J}=42 \mathrm{P}$; Boios, frg. $2.13 \mathrm{Ch} .=2.8 \mathrm{~J}=$ $44 \mathrm{P}$; Teutanos, frg. 2. $15 \mathrm{Ch} .=2.13 \mathrm{~J}=45 \mathrm{P}$; Sabinos, frg. 2. $21-22 \mathrm{Ch} .=1.6-7 \mathrm{~J}=50-51$ P; Marsos, Pelignos e Marrucinos, frg. 23 Ch. $=2.18 \mathrm{~J}=53 \mathrm{P}$; Tesuntos de Tauriano, frg. 3. $4 \mathrm{Ch} .=3.1 \mathrm{~J}=71 \mathrm{P}$.

6 Politório, cidade fundada por Polita, filho de Príamo e de Hécuba assassinado por Pirro, frg. 2. $24 \mathrm{Ch}=2.26 \mathrm{~J}=54 \mathrm{P}$; Bovilas, $2.25 \mathrm{Ch} .=2.27 \mathrm{~J}=55 \mathrm{P}$; Tíbur, cidade fundada pelo árcade Catilo, frg. $2.26 \mathrm{Ch}=2.24 \mathrm{~J}=56 \mathrm{P}$; santuário de Diana nas proximidades de Arícia, frg. 2. $28 \mathrm{Ch} .=2.21 \mathrm{~J}=58 \mathrm{P}$; Preneste, fundada por Céculo, frgs. 2. 29-30 = 2. 22- 
Os livros 4-7 foram escritos no fim da vida de Catão, começam com novo proémio e refletem acerca de assuntos como a constituição política de Cartago (frg. 4. $3 \mathrm{Ch}=4.6 \mathrm{~J}=80 \mathrm{P}$ ), a Primeira Guerra Púnica (264-241 a.C.; frg. 4. 7. a-b Ch = 4. 7-8 J = 83 - - P), a violação, pela sexta vez, do tratado por parte dos Cartagineses em 219 a. C. (frg. $9 \mathrm{Ch}=4$. $10 \mathrm{~J}=84$ P); a Batalha de Canas (216 a.C.; frg. 4. 12 Ch. = 4. $14 \mathrm{~J}=91 \mathrm{P}$ ); a vitória de Catão em Empórias (atualmente Ampúrias), na Hispânia Tarraconense, em 195 (frg. 5.1 Ch. = 5.12 J = 92 P); a oratio pro Rhodiensibus, proferida em 167, no rescaldo da vitória romana sobre a Macedónia em Pidna, em 168 [frgs. 5. 3. a-g Ch. = 5. 1-7 J = 95 a-g P = 163-169 O(ratorum) $R$ (omanorum) F(ragmenta; v. Malcovati) ${ }^{4}$; a terceira guerra da Ilíria (frg. 5. $4 \mathrm{Ch} .=5.8 \mathrm{~J}=96 \mathrm{P}$ ); a oratio contra Galbam, onde se condenava a personagem por ter feito um acordo com os Lusitanos, ter faltado à palavra, os ter chacinado e se ter servido de seus próprios filhos e do de Gaio Sulpício Galo para se defender em tribunal (frgs. 7. 1-4 Ch. = 7.1-3 a-b J = 106-109 P = 196-199 O. R. F. $\left.{ }^{4}\right) ;$ a defesa por Catão, em 195, da lex Oppia, promulgada 20 anos antes, contra os luxos das mulheres (frg. 7. $9 \mathrm{Ch}$. = 7. $8 \mathrm{~J}$ = $113 \mathrm{P}$ ); a posição de Catão em favor da lex Orchia (182 a. C.) ou da lex Fannia (161 a.C.), contra a sumptuosidade dos festins (frg. 7. 12 Ch. $=7.13 \mathrm{~J}=119 \mathrm{P})$.

Não cabe, no âmbito deste estudo, a especulação acerca dos motivos que terão levado Catão a omitir os primeiros séculos da República ou sobre o problema da unidade da obra. Importa, isso sim, notar que as Origines, de acordo com Cornélio Nepos, se organizam capitulatim, 'de acordo com os principais pontos' ( $\kappa \varepsilon \varphi \alpha \lambda \alpha \imath \omega \delta \tilde{\omega} \varsigma),{ }^{7}$ e com digressões de natureza cultural. Embora não seja possível determinar se, ao afirmar: Si ques homines sunt, quos delectat populi Romani gesta describere... (frg. 1. $1 \mathrm{Ch} .=1.1 \mathrm{~J}=1 \mathrm{P}$ ), estaria Catão a pensar em si próprio ou nos que o precederam, a verdade é que, do resumo apresentado e do fragmento

$23 \mathrm{~J}$ = 59-60 P; Cápua e Nola, fundadas pelos Etruscos, frg. 3. 1 Ch. = 3. 2 J = 69 P; Tebas, desaparecida da Lucânia, frg. 3. 2 Ch. = 3. 4 J = 68 P; Petélia, frg. 3. 3 Ch. = 3. 3 J = 70 P.

7 A tradução da forma latina é de Leo e Bömer apud Albrecht 1997: 397 n. 3. 
citado, facilmente se conclui que a historiografia é o género que maior influência exerce nas Origines.

Ao refletir sobre as diferenças entre a poesia e a História, havia Aristóteles, Po. 8. 1451b 1-10, observado que a primeira, ao tratar o que poderia suceder de acordo com a necessidade e a verosimilhança, era mais universal e filosófica do que a segunda que, ao relatar o que tinha sucedido, visava o particular. Mas se tal distinção se compreende no âmbito de uma poética explícita, a verdade é que, na implícita, o problema não era tão linear, tanto mais que, do mesmo modo que se poderiam encontrar aspetos históricos na poesia, na filosofia e em obras médicas, assim continha a historiografia elementos romanescos, genealógicos, etnográficos e geográficos. ${ }^{8}$ Não é, além disso, por acaso que Heródoto associa a sua historiografia a um propósito laudatório, recorre aos míticos raptos (Io, Europa, Medeia e Helena) para justificar o início da animosidade entre a Europa e a Ásia, oscila entre a abstenção de tomar posição face à tradição oral, a aceitação, a tentativa de racionalização dos relatos que lhe chegam, a descrença e o ceticismo perante as versões tradicionais, e reflete apreço pelo mito, pelo romanesco e pelo anedótico. ${ }^{9}$ Tito Lívio revelará igualmente consciência do problema ao justificar, com um propósito de embelezamento e de engrandecimento e com uma dimensão paradigmática e didática, o recurso a lendas poéticas, que, como o próprio reconhecia, não tinha intenção de confirmar ou refutar. ${ }^{10}$

8 Cf. Toynbee apud Rocha Pereira 2012: 285.

9 Rocha Pereira 2012: 288-92.

10 Quae ante conditam condendamue urbem poeticis magis decora fabulis quam incorruptis rerum gestarum monumentis traduntur, ea nec adfirmare nec refellere in animo est. Datur haec uenia antiquitati ut miscendo humana diuinis primordia urbium augustiora faciat; ...

Hoc illud est praecipue in cognitione rerum salubre ac frugiferum. Omnis te exempli documenta in inlustri posita monumento intueri; inde tibi tuaeque rei publicae quod imitere capias, inde foedum inceptu foedum exitu quod uites. Ceterum aut me amor negotii suscepti fallit, aut nulla unquam res publica nec maior nec sanctior nec bonis exemplis ditior fuit, nec in quam [ciuitatem] tam serae auaritia luxuriaque immigrauerint, nec ubi tantus ac tam diu paupertati ac parsimoniae honos fuerit. 
Tito Lívio alude concretamente à "mistura do humano com o divino". No relato que faz da conceção de Rómulo e Remo, Dionísio de Halicarnasso, o principal testemunho do tratamento do tema por Catão, mostra-se algo ambíguo. Em Antiquitates Romanae 1.77. 1-2 informa que havia quem cuidasse que Reia Sílvia (Ília) teria sido violada no pequeno bosque consagrado a Marte por alguém que a teria seguido e estaria apaixonado por ela, quem pensasse que o violador teria sido o próprio tio, Amúlio, e quem - a maior parte dos escritores - atribuísse o ato à sombra do próprio deus, alegando o desaparecimento em simultâneo do sol, o escurecimento do céu, a superior estatura e beleza do espetro e as palavras de conforto que, no final, teria dirigido à vítima, onde lhe teria anunciado o nascimento de dois gémeos mais corajosos que os homens. Embora se pressinta alguma preferência pela última hipótese, o narrador passa, após considerações de caráter teológico que infra referiremos, a considerar a simulação de doença por parte de Reia Sílvia (1. 77. 4).

A ambiguidade regressa porém ao relato de Dionísio de Halicarnasso em 1. 78. 1, pois o narrador, sem fazer qualquer referência a fonte de informação alguma, admite a possibilidade de Amúlio estar a par do ocorrido ou de apenas suspeitar. Depois de anunciar ao conselho a gravidez da moça, Amúlio, que facilmente se poderia imaginar incapaz

Quanto aos factos anteriores à fundação da cidade ou ao plano de a fundar, embelezados por lendas poéticas, mais do que transmitidos por documentos inalterados dos acontecimentos, não tenho em mente nem confirmá-los nem refutá-los. À antiguidade dá-se vénia para tornar mais augustos os primórdios das cidades pela mistura do humano com o divino...

O que há de mais salutar e fecundo no estudo da história é que se contemplam os ensinamentos de toda a espécie de exemplos dispostos num momento bem visível; daí se podem extrair modelos a imitar para uso próprio e do seu país, e atos vergonhosos a evitar pelas suas causas ou pelas suas consequências. De resto, ou o entusiasmo pela minha empresa me ilude, ou jamais algum país foi maior, mais puro, mais rico em bons exemplos nem levaram tanto tempo a entrar numa cidade a avareza e o luxo, nem a tal ponto nem durante tanto tempo a pobreza e a parcimónia ocuparam lugar na terra (Tito Lívio, praef., 6-7, 10-11; lição de Conway \& Walters 1955; trad. de Rocha Pereira 2010: 211; a adaptação ao AO 1990 é minha). 
de assumir publicamente a responsabilidade pelo crime, no caso de o haver efetivamente cometido, insta o pai de Ília, Numitor, a revelar a identidade do pai da criança (1.78. 2). A ambiguidade parece contudo desvanecer-se em 1. 78.3, quando a esposa de Numitor o informa de que Reia Sílvia havia confessado ter sido violada por um deus que, por sua vez, lhe anunciara o nascimento de valorosos gémeos - e são estas as informações que o pai da jovem transmite ao conselho. 0 nascimento efetivo dos gémeos é para Numitor e os membros do conselho a prova acabada da união de Ília com o deus (1. 78. 4).

Se, para relatar o que tinha sucedido após o nascimento de Rómulo e Remo, o mesmo Dionísio de Halicarnasso, Antiquitates Romanae 1. 79. 4-1. 83.3 (= frg. $1.16 \mathrm{Ch} .=1.15 \mathrm{~J}=15 \mathrm{P}$ ), confessa ter-se servido da versão de Quinto Fábio Píctor, seguida por Lúcio Cíncio, Pórcio Catão, Calpúrnio Pisão e outros historiógrafos, afigura-se deveras tentadora a inclusão de Catão no grupo de escritores que teria seguido a versão do mito que atribuíra a Marte a paternidade de Rómulo e Remo. Partindo por conseguinte deste pressuposto, três alternativas se nos afiguram: ou Catão acreditava que tal união entre o deus Marte e a humana Reia Sílvia tivera existência real, ou, não crendo na historicidade de tal união, dela se servira apenas para engrandecer, num plano meramente ficcional, os primórdios da Urbe, ou hesitava entre a crença e a descrença. Em 1. 77. 3, abstém-se formalmente Dionísio de Halicarnasso de desprezar fábulas que projetem nos deuses as fragilidades humanas e de admitir a existência, entre a raça dos deuses e a dos homens, de daimones que se uniriam aos primeiros ou aos segundos e gerariam a raça dos heróis - e, para justificar a sua atitude, alega, em 1. 77. 4, que os filósofos já tinham dito o suficiente sobre o assunto. Se Dionísio de Halicarnasso tivesse coincidido com Catão na referida ausência de uma tomada de posição sobre um tema tão debatido pelos filósofos, talvez a atitude de ambos os autores fosse precursora da do Tito Lívio que não tinha a intenção de confirmar ou infirmar os vários relatos mais ou menos lendários sobre os primórdios da Urbe. Em todo o caso, na hipótese 
de Catão ser adepto da versão que preconizava uma união entre Reia Sílvia e Marte, mesmo que não manifestasse a sua opinião acerca da historicidade do acontecimento, isso não significa que a não tivesse ou que não hesitasse entre a crença e a descrença, e que os seus leitores contemporâneos se não comportassem do mesmo modo.

Ao considerar o papel do leitor na definição do fantástico e de géneros que com ele fazem fronteira, escreveu Tzvetan Todorov: "O fantástico, já o vimos, dura só o tempo de uma hesitação: hesitação comum ao leitor e à personagem, que devem decidir se aquilo que percecionam pertence ou não à «realidade» tal como ela existe para a opinião comum. Se ele decidir que as leis da realidade ficam intactas e permitem explicar os fenómenos descritos, diremos que a obra depende doutro género: o estranho. Se, pelo contrário, ele decidir que se devem admitir novas leis da natureza, através das quais o fenómeno pode ser explicado, entramos no género maravilhoso."11

Se se tomar em consideração que, antes, já Todorov dispensara o papel da perceção por parte da personagem na definição do fantástico, facilmente se conclui que, enquanto leitor de Quinto Fábio Píctor e eventualmente transmissor da versão do mito que sustentava a união de Reia Sílvia e Marte, Catão poderia, de algum modo, refletir as crenças dos seus próprios leitores, que, no caso de hesitarem entre a historicidade e a não-pertença à "realidade", colocariam o episódio no domínio do fantástico; no caso de se decidirem pela primeira hipótese, o situariam no âmbito do estranho; e, no de buscarem novas leis da natureza para o explicarem, o enquadrariam no maravilhoso. Para o leitor moderno, a união de Reia Sílvia e Marte, como a de nautas e ninfas na Ilha dos Amores camoniana, não passa de uma lenda ou de um mito com contornos de maravilhoso.

Algo diverso se passa, no entanto, com a perceção atual da segunda parte, digamos assim, deste episódio. A propósito do início de vida dos 
recém-nascidos Rómulo e Remo, conta Dionísio de Halicarnasso, no resumo da versão veiculada pelos historiógrafos referidos, que, lançados numa cesta a partir do sopé do Palatino às águas transbordantes do Tibre, os bebés foram levados pela corrente até que o nível das águas desceu, a cesta encalhou numa pedra e se virou. Rómulo e Remo começaram a debater-se na lama e desataram aos gritos, quando apareceu uma loba, que, com as tetas cheias de leite, lhas encostou à boca e, com a língua, tratou de lhes limpar o lodo que os recobria. o cuidado que o animal punha no que fazia suscitou tal admiração e incredulidade

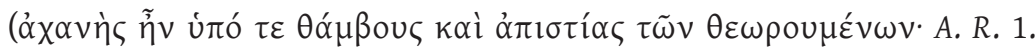
79. 5) de um dos pastores que passavam com os seus rebanhos, que tratou de chamar os restantes para verem acontecimento tão notável. Dionísio de Halicarnasso chega mesmo a dizer que, ao testemunharem a afeição recíproca de loba e bebés, os pastores chegaram a cuidar

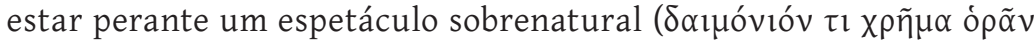

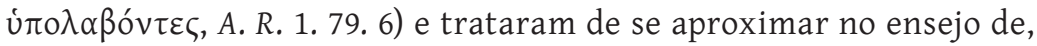
com os gritos, assustarem a loba, que, por seu turno, não fugiu, mas se afastou calmamente dos recém-nascidos, sem prestar a menor atenção ao tropel dos pastores.

Na medida em que a reação dos pastores pode constituir uma pista, facultada eventualmente por Catão e indubitavelmente por Dionísio de Halicarnasso, para condicionar a resposta dos leitores ao relato, talvez se possa admitir que, para os referidos autores e seus leitores, esta parte do episódio se enquadrasse no domínio do estranho, mas o problema é que, ao contrário dos pastores, talvez os autores e leitores nunca tivessem presenciado semelhante fenómeno, pelo que muitos dos últimos seguramente haveria que o considerariam maravilhoso. Ainda a propósito das respostas antigas ao relato, escreveu Beard: "A loba a amamentar os gémeos é um tão estranho episódio num conto muito peculiar, que até os escritores na Antiguidade mostraram, por vezes, 
um ceticismo saudável acerca do aparecimento de um animal convenientemente lactante para amamentar o par de bebés abandonados."12 Grimal, Nieto, Leão e Brandão realçam a dimensão lendária e fabulosa do episódio. ${ }^{13}$ Grimal parte do pressuposto de que a loba, na tal versão lendária, teria sido enviada por Marte, pai de Rómulo e Remo; Leão e Brandão admitem, com base numa estatueta de bronze do animal, provavelmente do séc. VI a.C., e na presença do motivo em moedas cunhadas em 269 a.C., que a lenda já circularia na época arcaica e não seria adversa aos propósitos de Roma, e recordam várias teorias de ordem religiosa, mitológica, étnica, política, social e linguística para a justificarem.${ }^{14}$ A propósito do ritual da fundação da cidade de Roma, chega Grimal a afirmar: "É certo que os Romanos não acreditavam nesta

12 Beard 2016: 61.

13 Nieto 2006: 45; Grimal 2009: 17; Leão \& Brandão 2015: 32.

14 Grimal 2009: 17; Leão e Brandão 2015: 32 n. 10: "Pode significar o culto totémico do lobo (próprio de civilizações pastoris); temas mitológicos greco-etruscos (cerva de Télefo e a loba de Bolónia); dualidade étnica (Romanos e Sabinos) ou política (patrícios e plebeus), através de duas etimologias (grega Rhomos e latina Romulus) para o epónimo do fundador da cidade. Tudo enquadrado numa cenografia local: gruta do Palatino ( $\mathrm{Lu}$ percal) e figueira (Ruminal). O nome da figueira deriva do facto de ficar junto do santuário de Rumina, uma divindade protetora das aleitantes. De resto, como o alfabeto etrusco não tinha a vogal o, o nome de Roma era escrito naquela língua como Ruma, o que em latim significava 'teta'." Os referidos investigadores ainda consideram a possibilidade de Roma estar para Romulus como a Sicilia para Siculus, 'siciliano', e de, por conseguinte, "não ter existido nenhum herói com esse nome" (33); realçam a tradição popular que valoriza a importância de certos heróis em determinadas sociedades (Ciro na Pérsia; os troianos Páris e Eneias; os gregos Perseu e Édipo; Egisto, conspirador contra Agamémnon em Argos; Cípselo, tirano de Corinto), ou faz remontar a heróis a origem de cidades e povos (Iónios provenientes de Íon). Grimal 2009: 17 e Leão \& Brandão 2015: 33 ainda notam relação etimológica entre fauere, 'favorecer', e Fáustulo, e a proximidade entre este nome próprio e Fauno, deus pastoril cultuado no Lácio; e a de Aca Larência aos Lares. Por fim referem a confluência nos Larentalia (festividade celebrada a 23 de dezembro) do culto dos mortos e de lendas de fecundidade, e o facto de, no final da República, ainda se poder ver no Palatino a cabana da Fáustulo, em adobe e encimada por colmo. Montanelli 1997: 10 admite que não passe de mexerico a possibilidade de a loba não ter sido um animal, mas uma alcunha de Aca Larência, decorrente do seu caráter selvagem e das infidelidades ao pastor Fáustulo. 
história, mas aceitavam-na; sabiam que a sua cidade não era apenas um conjunto de casas e templos, mas um espaço de solo consagrado (o que as palavras pomerium e templum exprimem, em diversos casos), um local dotado de privilégios religiosos, onde o poder divino se encontra particularmente presente e sensível." ${ }^{15}$ À luz desta conclusão se percebe a preocupação de Grimal em associar a Marte a loba. Se o investigador pretender alargar esta conclusão ao episódio da loba, as palavras de Dionísio de Halicarnasso deixam no ar dúvidas que tornam a generalização algo abusiva.

À exceção das teorias que defendem a inexistência de Rómulo e de Aca Larência, nenhuma das apresentadas se revela absolutamente incompatível com a possibilidade de uma loba real ter amamentado dois gémeos expostos, pelo que, ao conjugar a caraterização do "episódio" como "tão estranho" e do "conto" como "muito peculiar" com a do "ceticismo" como "saudável”, a perspetiva de Beard não só se revela a mais prudente e cautelosa relativamente à confluência de um conjunto de circunstâncias felizes, como, ainda que talvez de forma literariamente inconsciente, a terminologicamente mais precisa de todas. É que, para muitos leitores atuais, conhecedores do caso das duas jovens que por volta de 1920 foram encontradas no norte Índia, a viver com uma alcateia, e resgatadas por caçadores que chacinaram os lobos - alguns anos depois, portanto, de Rudyard Kipling ter publicado o Livro da Selva, em 1894 - esta parte do episódio relatada pelos historiógrafos latinos não passa de algo suscetível de se enquadrar no género estranho. ${ }^{16}$

15 Grimal 2009: 18.

16 Vale a pena, a este propósito, ler o capítulo intitulado "As composições lendárias e as narrativas históricas”, em Malson 1988: 43 ss., onde, após recordar o facto de Heródoto ter relatado casos de crianças isoladas, e depois de ter aludido ao episódio da vida de Tiro com as éguas, de Júpiter que teria mamado em Amalteia, da Loba que teria amamentado Rómulo e Remo, da criança que, no tempo da conquista goda, teria sobrevivido entre ruínas e agarrada ao úbere de um animal, às lendas persas de ursos-precetores e, entre outras, às japonesas de macacos-amas, observa o autor: "Apesar de tudo seria necessário, com Max Müller ou Frazer, considerar a parte de verdade que encerra o pensamento mítico que, desde a descrição do dilúvio à narração da Tebaida, 
Mas, nas Origines, é possível encontrar um passo onde o género fábula se articularia, de forma subordinada, com o relato mais amplo de um momento da história de uma cidade. Trata-se do frg. 3. 5 Ch. = 3. $5 \mathrm{~J}=72$ P, onde se pode ler: Equos respondit: 'Oreas mihi inde, tibi cape flagellum.' "O cavalo respondeu: “Coloca-me o bridão, mune-te de chibata.”" Para se contextualizarem estas palavras na história da cidade de Hímera, vale a

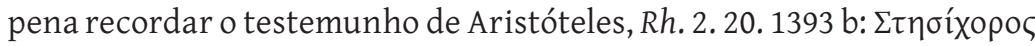

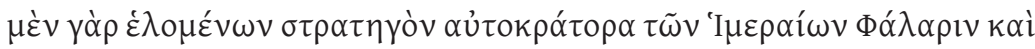

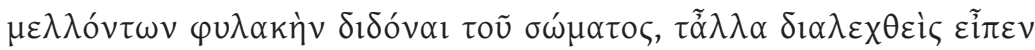

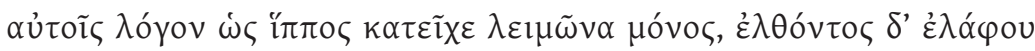

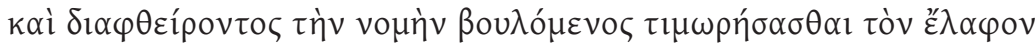

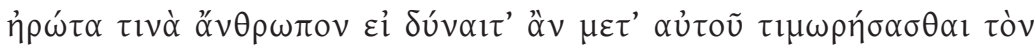

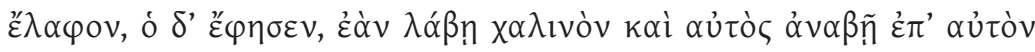

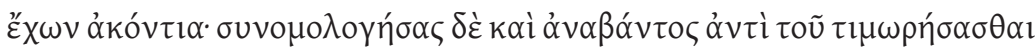

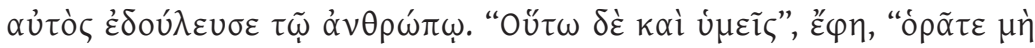

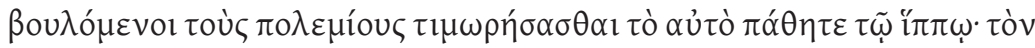

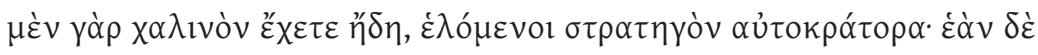

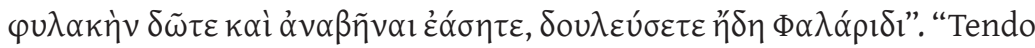
os cidadãos de Hímera escolhido Fálaris como estratego com plenos poderes, e estando a ponto de lhe atribuir uma escolta pessoal, Estesícoro, entre outras considerações, contou-lhes a fábula seguinte: um cavalo tinha um prado só para si, mas chegou um veado e estragou-lhe o pasto; o cavalo, querendo então vingar-se do veado, perguntou a um homem se o podia ajudar a punir o veado. O homem consentiu, com

exprime não apenas as metamorfoses da natureza mas também os dramas do homem, e converte em imaginários acontecimentos perfeitamente reais. É necessário também não rejeitar precipitadamente os textos das testemunhas, apenas porque entre eles se incluem alguns que são falsos. De tempos a tempos, a grande imprensa refere-se à descoberta de um novo Mowgli, que espera um Kipling para lhe narrar as aventuras. Abundam os retratos suspeitos, como de resto também na pintura. Refutar, baseando-se nos exemplos falsos, a validade de todos os que foram referidos, seria o mesmo que negar a existência de Vermeer, a partir do instante em que se adquiriu a certeza de que Megeren foi um falsificador." Sobre os casos de Amala, encontrada com 2 anos, e de Kamala, encontrada com 8 anos em Midnapore, Índia, v. Malson 1988: passim. 
a condição de lhe pôr um freio e montar nele com uns dardos. Feito o acordo, o homem montou o cavalo e este, em vez de se vingar, tornou-se escravo do homem. «Assim também vós», disse ele, «acautelai-vos, não vá acontecer que, querendo vingar os vossos inimigos, venhais a sofrer a sorte do cavalo; já tendes o freio ao eleger um estratego pleno de poderes; se lhe dais uma guarda pessoal e permitis que vos monte em cima, então sereis escravos de Fálaris»."17

Embora o cotexto aristotélico imediato confira à fábula uma dimensão política, a verdade é que ela surge em um subcapítulo dedicado ao "argumento pelo exemplo" e no decurso da divisão das provas comuns a todos géneros em dois tipos, o exemplo e o entimema; da caraterização do exemplo como algo semelhante a uma indução, isto é, a um princípio; da divisão do exemplo em duas espécies, a que reporta factos anteriores e a que diz respeito aos factos inventados pelo orador; e da distinção, no âmbito da última, entre parábola e fábulas. Como Aristóteles punha a tónica no caráter inventado dos factos, admite Todorov, no mesmo capítulo onde considerara a importância do leitor na definição dos géneros fantástico, estranho e maravilhoso, a existência de um "maravilhoso puro", que se não carateriza pela "atitude para com os acontecimentos narrados", mas pela "própria natureza dos acontecimentos", e ilustra-o com os contos de fadas, onde, entre os "acontecimentos sobrenaturais" que "não provocam" no leitor "nenhuma surpresa", refere "o lobo que fala". ${ }^{18}$ À luz da definição de Todorov, facilmente se conclui que a fábula do cavalo falante pertence o género maravilhoso. Se prestarmos atenção ao texto aristotélico,

17 Lição de Ross 1959; trad. de Alexandre Júnior, Farmhouse Alberto e Nascimento Pena 1998: 148. No comentário ao frg. de Catão, observa Chassignet 1986: 33 que, na versão de Cónon, também inspirada em Estesícoro, Gélon aparece no lugar de Fálaris, que não era tirano de Hímera, mas de Agrigento (F. Gr. Hist. 26 F 1 (XLII)), e nota a existência de uma outra versão da fábula veiculada por Filisto, historiador de Siracusa (Téon, Progymn. P. 26 Spengel). Hímera ficava $38 \mathrm{~km}$ a sudeste de Palermo (Sicília), próxima da embocadura do Fiume Grande.

18 Todas as expressões são citadas de Todorov 1977: 51-52. 
verificamos que se trata de dois planos distintos, o da realidade e o da fábula, que apenas coincidem na metáfora dos cidadãos com o freio posto e o tirano montado.

Do resumo e das considerações até agora tecidas, facilmente se vislumbram, nas Origines, as influências da historiografia, da geografia, da etiologia, do direito, da religião, da fábula, mas, além destas, ainda se poderiam referir, a propósito de passos ainda não considerados, as da medicina intimamente ligada à culinária, da etnografia e da agricultura (cf., p. ex., frg. 2. 14 Ch. $=2.10 \mathrm{~J}=43 \mathrm{P}$, sobre a produtividade vínica do ager Gallicus Romanus). Ora é precisamente nos dois últimos domínios que se enquadra o testemunho de Varrão, R. 2. 4. 11, que veicula o frg. $2.9 \mathrm{Ch} .=2.11 \mathrm{~J}=39 \mathrm{P}$ das Origines de Catão. Muitas têm sido as conjeturas em torno do fragmento. Na edição da Loeb da obra de Varrão, por exemplo, onde a tradução de Hooper e Ash se baseia na lição da Teubner, da responsabilidade de Goetz e datada de 1929, pode ler-se: In Italia Insubres terna atque quaterna milia aulia succidia uere.... ${ }^{19}$ “Os Ínsubres, na Itália, salgam três ou quatro mil pedaços; na primavera...." Os Ínsubres eram um povo da Gália Transpadana, mas a alteração, proposta por Turnèbe, colide com a lição dos códices (in scrobes), conforme A. Popma a conservou na sua edição Catão datada de 1601, e L. Alfonsi - A. Roncoroni e Chassignet a recuperaram. ${ }^{20}$

Hamblenne, por sua vez, propôs a seguinte leitura: In Italia, in scrobes terna atque quaterna milia [aulia] <su(um) seu sues> succern(un)t uere.... ${ }^{21}$ "Na Itália, põem de parte em fossas três e mesmo quatro mil porcos a cada primavera...." O investigador sustenta que "os Gauleses" são o sujeito subentendido da frase; recorda que, de acordo com Varrão, era no final do inverno que se punham de parte varrões e porcas com uma idade entre os doze e os vinte ou vinte e quatro meses para que se verificassem as primeiras cópulas; admite a possibilidade de, fecundadas as

19 Hooper \& Ash 1935: 356.

20 Chassignet 1986: 70, n. 9. 1; Hamblenne 2000: 89-90 e 95.

21 Hamblenne 2000: 100. 
porcas, destas se apartarem, na primavera e por motivos de segurança das prenhes, fêmeas pouco produtivas ou esterilizadas e porcos castrados; e conclui: “C'est au début de la bonne saison encore qu'il faut normalement décider quels porcs on laissera chercher leur provende siluestri loco, et lesquels on maintiendra dans un enclos pour qu'ils engraissent." ${ }^{22}$ A propósito das pocilgas onde se criariam os suínos em regime de engorda intensiva, fala Hamblenne de fossas no chão, de passadiços que permitiriam o acesso às fossas, de muros laterais que protegeriam do vento e de pilares que suportariam um teto. ${ }^{23}$ A leitura proposta pelo investigador é engenhosa, mos o próprio reconhece que, na ausência de testemunhos arqueozoológicos e literários que esclareçam, de forma inequívoca, o sentido de "un témoignage unique de Caton, suivi de deux mirabilia", mais não tece do que um conjunto de conjeturas de base lexicográfica.

Publicada em 2000, portanto entre a primeira edição de Les Belles Lettres das Origines, datada de 1986, e uma segunda tiragem, de 2002, não encontrou a proposta de Hamblenne qualquer tipo de eco em Chassignet, a fixadora do texto na referida edição, que, na mencionada tiragem, continuou a ler: In Italia in scrobes terna atque quaterna milia [aulia] succidiarum uehere. Sus usque adeo pinguitudine crescere solet, ut se ipsa stans sustinere non possit neque progredi usquam. Itaque eas si quis quo traicere uolet, in plaustrum imponit. "Na Itália transportam-se para covas três ou quatro mil pedaços de carne salgada de porco. A porca costuma medrar de tal sorte em banha, que por si própria se não consegue suster de pé e muito menos avançar. E assim, se alguém a quiser transportar para algum lado, põe-na em cima de uma carroça."

Quanto à historicidade da técnica de armazenamento do toucinho, não oferece quaisquer dúvidas, pois, após explicar que os scrobes eram

22 Hamblenne 2000: 100.

23 Hamblenne 2000: 102. 
"cavités garnies d'argile", notou Chassignet, baseada em F. Chevallier: "Ce type de saloir a subsisté jusqu'au XX ${ }^{e}$ siècle dans le nord-ouest de la France." ${ }^{24}$ Da veracidade da informação acerca da quantidade de carne de porco armazenada, talvez se não deva também duvidar, visto que Políbio 2. 14.7 e 2.15. 2-3 informa que a planície da Gália Cisalpina ultrapassava em produtividade qualquer outra região conhecida da Europa, e que os seus bosques produziam tal quantidade de bolota e alimentavam tantos suínos que quase satisfaziam as necessidades deste tipo de carne por parte da população e do exército da Itália.

No caso do ser humano, a obesidade mórbida pode efetivamente colocar problemas à locomoção da pessoa. Quanto a suínos que sofram de claudicação ou coxeira, prevê Decreto-Lei português n.․ 28/96 que, na impossibilidade de serem transportados sem acréscimo de sofrimento para os próprios, o abate se faça na própria exploração. o documento onde encontrei a alusão ao referido Decreto-Lei, ainda admite a possibilidade de "uma percentagem significativa de animais apresentar claudicação severa"25. É sabido, além disso, que a submissão de uma porca nulípara a uma dieta de engorda não favorece o adequado desenvolvimento de unhas, ossos e cartilagens. Ainda se vê, em algumas aldeias, o transporte de varrões em carretas para os currais das porcas. Ora com base nestes dados e na sequência de informações de indiscutível veracidade, poderia o leitor moderno sentir-se tentado a cuidar verídica a parte final do fragmento transcrito, onde se alude à acumulação anormal de tecido adiposo por parte da porca, que representa a generalidade das fêmeas da espécie na Gália Cisalpina, à impossibilidade de se manter de pé e de se locomover, e à necessidade de uma carroça para a transportar. Contudo, no que toca o ser humano, é difícil encontrar numa determinada região uma grande concentração de pessoas que

24 Chassignet 1986: 70 ad loc.

25 Cf. p. 87 de secção intitulada "Suínos" de documento que, a 29 de março de 2017, se encontrava em: http://www.lusogenes.pt/Documentos\%20PDF/Legisla\%C3\%A7\%C3\%A3o/ BemEstarSuinos_recomendacoes.pdf. 
padeçam de obesidade mórbida e tenham dificuldades de locomoção. Importa ainda reiterar a ideia de que a forma verbal solet sugere que Catão não está a falar de um caso isolado, mas a generalizar.

Se dúvidas restassem quanto ao caráter no mínimo abusivo de tal generalização, dissipá-las-ia o confronto do passo de Catão com um testemunho de Estrabão 4.4.3, a propósito do modo de vida dos Gau-

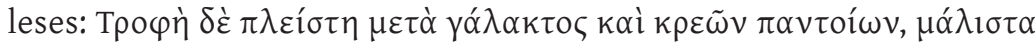

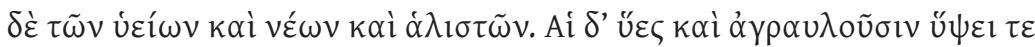

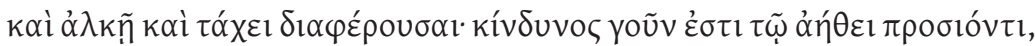

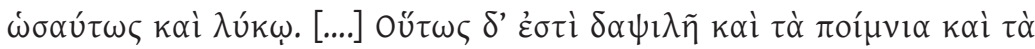

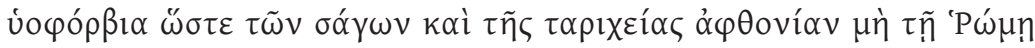

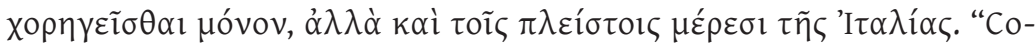
mida têm eles em abundância, juntamente com leite e carne de toda a sorte, mas sobretudo de porco, não só fresca mas também salgada. Os seus porcos criam-se ao ar livre, avantajados em altura, intrepidez e rapidez; incorre certamente em perigo o estranho que deles se aproximar, e de igual sorte também um lobo. [....] Tão magníficos são não só seus rebanhos de ovelhas como também suas varas de porcos, que fornecem fartura de sagos e carne salgada, não só a Roma, mas também à maior parte da Itália."

É certo que se pode alegar que Catão falara de uma porca, ilustrativa é certo de um costume, ao passo que Estrabão descreve porcos, mas não me parece que as porcas estejam excluídas do relato do último e que o tipo de alimentação de porcas e porcos fosse diverso. Se fizessem uma alimentação que favorecesse a acumulação de tecido adiposo, não teriam as porcas e os porcos condição de lutar com lobos e humanos. Perante tudo isto, fica o leitor moderno tentado a acreditar na possibilidade da existência de porcas claudicantes, mas se, como os seus companheiros porcos da Gália Cisalpina, a maior parte das porcas era alta, intrépida, rápida e feroz para estranhos e lobos, as claudicantes não podiam constituir a regra, mas a exceção. O caso, conforme se pode ver, suscita ao leitor moderno muitas dúvidas, que, enquanto 
permanecerem, o situam no domínio do fantástico, e, se se desvanecerem, o passam para o do estranho ou, de forma menos provável, para o do maravilhoso hiperbólico. ${ }^{26}$ Enquanto o leitor antigo poderia visitar a Gália Cisalpina ou falar com pessoas da região, já nós, leitores atuais, conseguimos aceder via internet a um folheto de bem-estar suíno, mas o confronto do passo com o testemunho de Estrabão tantas dúvidas suscitaria no leitor antigo, como no moderno, quando se trata de determinar a conformidade da informação nele veiculada com a “《realidade» tal como ela existe para a opinião comum” (Todorov).

Quanto à ligação da obra literária à realidade quotidiana, afirma Aristóteles que nada obsta a que fatos efetivamente ocorridos sejam possíveis e verosímeis (Po. 9. 1451b 29-32). Daqui se depreende a presença do verosímil em obras de forte pendor historiográfico, como as Origines. Mas, do mesmo modo que Aristóteles, Po. 24. 1460a 26 60b 2 (cf. 15. 1454a 37 - 54b 8), admite a possibilidade de dissimular o irracional e o absurdo com boas qualidades, de modo a conferir à totalidade do enredo verosimilhança, também Catão, para se tornar convincente, articula factos de veracidade indiscutível com outros de historicidade duvidosa, como no fragmento analisado. Por isso conclui Todorov 1977: 45: "A verosimilhança não se opõe portanto de maneira nenhuma ao fantástico: a primeira é uma categoria que se distingue pela coerência interna, pela submissão ao género, enquanto o segundo se refere à perceção ambígua do leitor e da personagem. No interior do género fantástico é verosímil que se deem reações "fantásticas»." Vale, no entanto, a pena notar que, ao contrário do que recomenda Aristóteles, em Po. 24. $1460^{\text {a }}$ 26-27, não prefere Catão, no fragmento citado, o impossível verosímil ao possível inverosímil.

A reflexão já vai longa, mas não pode omitir mais dois fragmentos catonianos que ao leitor moderno suscitam reservas quanto à

26 A propósito do maravilhoso hiperbólico, escreve Todorov 1977: 52: “Os fenómenos não são aqui sobrenaturais senão pelas suas dimensões, superiores às que nos são familiares." 
veracidade da informação veiculada. Falamos do frg. $2.20 \mathrm{Ch}=2.16 \mathrm{~J}$ = 52 P: In Sauracti <et> Fiscello caprae ferae sunt, quae salient e saxo pedes plus sexagenos. "No Soracte <e> no Fiscelo há cabras selvagens que saltam de uma rocha com mais de sessenta pés." Cada pé corresponde a 0.296 m., e, por conseguinte, Catão fala de um salto de mais de 17. 76 metros. Se se tomar em consideração que, em março de 2017, Nelson Évora revalidou o título de campeão europeu de triplo salto com um ensaio de 17. 20 m., não seria de estranhar uma espécie de triplo salto de uma cabra a descer as encostas dos referidos montes, mas, quando se trata de uma queda de uma altura superior a 17. 76 m., é assunto em que não acreditamos com facilidade. Importa, contudo, notar que Catão não diz se as cabras sobrevivem ou não à queda, pois, no caso de não sobreviverem, a informação já se tornaria mais condizente com a realidade. Mas a forma salient sugere salto - e não queda - e convicção de uma certa segurança. Em todo o caso, se me dissessem que, quase na fronteira da Itália com a Suíça, há um tipo de cabra, Ibex Europeu (Ibex Alpine, Ibex de Capra), que se alimenta de musgo, flores e sais minerais, na barragem de Cingino, a muitos metros de altura e com uma inclinação muito elevada, não acreditaria, mas o YouTube mostra que é verdade. ${ }^{27}$ Tudo isto contribui para a permanência da dúvida e, por conseguinte, do domínio do fantástico.

Ao descrever geográfica e etnograficamente a Hispânia, escreve Catão, Origines, frg. 5. 2 Chassignet (7. $5 \mathrm{~J}=93 \mathrm{P})$ : Sed in his regionibus ferrareae, argentifodinae pulcherrimae, mons ex sale mero magnus; quantum demas, tantum adcrescit. Ventus Cercius, cum loquare, buccam implet, armatum hominem, plaustrum oneratum percellit. "Mas nestas regiões há belíssimas minas de ferro e de prata, uma grande montanha de sal puro; quanto se retira, tanto aumenta. $O$ vento Círcio, quando se fala, enche a boca, derruba um armado homem, uma carroça carregada."

27 Disponível em https://www.youtube.com/watch?v=boL7ivYeDrs a 31.3. 2017. 
Em comentário à afirmação de Catão acerca da atividade mineira no vale do Ebro, observa Chassignet que as referidas jazidas de ferro e de prata não eram as mais ricas da península, mas, baseada em Plutarco, Cat. Ma. 10. 4, e Lívio 34. 46. 2, lembra que Catão deu uma libra de prata a cada militar do seu exército e, no rescaldo do triunfo de 194 e no que foi a maior transferência da Hispânia para Roma, contribuiu com 25.000 libras de lingotes de prata e numerosas moedas para o Aerarium. ${ }^{28}$

Quanto às dúvidas acerca da veracidade das informações sobre a montanha de sal, procura Chassignet dissipá-las ao informar que a referida montanha existia perto de Cardona, na província de Barcelona, teria uma altura de 124 metros, quatro quilómetros de perímetro e - ao contrário da mina de Egelasta, cujo sal era o preferido para fins medicinais - não era referida em mais texto algum. Apesar desta nota, Albrecht não se mostra muito convencido da veracidade da afirmação, ${ }^{29}$ e eu sinto-me deveras tentado a situar o passo catoniano no domínio do maravilhoso hiperbólico ou do exótico. ${ }^{30}$ Não se trata, no caso do maravilhoso exótico, da descrição de um lugar distante no espaço, que o leitor implícito não conhece e de cujas peculiaridades não tem motivos para duvidar, mas antes de um lugar que, para o leitor moderno, se encontra distante no tempo e muito difere da perceção comum que atualmente se tem do referido espaço.

A propósito da forma Cercius, para designar o vento, sugerem Aulo Gélio 2.22. 28 e Apuleio, Mun. 321, que a mais comum é Circius; e Chassignet observa que o vento Círcio sopra de noroeste para sudeste na Narbonense e no vale do Ebro. ${ }^{31} \mathrm{~J}$. Beaujeu, referido pela autora, identifica-o com o cierzo catalão. O equipamento de um legionário do séc. II a.C., de acordo com Chassignet, pesaria entre 18 e $20 \mathrm{~kg}$. Uma carroça das antigas poderia transportar uma carga até $650 \mathrm{~kg}$. Só se o autor se

28 Chassignet 1986: 93 ad loc.

29 Albrecht 1997: 398.

30 Todorov 1977: 52.

31 Chassignet 1986: 93. 
estiver a referir a tufões, com rajadas de vento de $360 \mathrm{~km}$ por hora.... Enfim, Albrecht não se mostra muito convicto acerca da veracidade da informação, ${ }^{32}$ e, para mim, este passo é do domínio do fantástico.

A presença do fantástico na literatura greco-latina e em particular na historiografia não é uma novidade catoniana: já existia na literatura latina e grega. o fantástico tem origem rural e pode recorrer a uma técnica semelhante à da inclusão do alogon na tragédia, que passa por misturar a verdade com o duvidoso, para se tornar convincente. Importa, finalmente, ter presente que, em muitos casos, apesar de termos mais informação disponível do que antigamente, não ficamos mais esclarecidos no que à determinação dos limites do fantástico diz respeito, pois os textos antigos não coincidem nas informações veiculadas ou a perceção que atualmente temos do espaço difere muito da veiculada por uma única fonte antiga. Assim se avolumam legítimas dúvidas.

\section{BIBLIOGRAFIA}

Albrecht, M. von (1997), A history of Roman literature: from Livius Andronicus to Boethius. Leiden - New York - Köln.

Alexandre Júnior, M.; Alberto, P. Farmhouse; Pena, A. do Nascimento (1998), Aristóteles. Retórica. Lisboa.

Beard, M. (2016), SPQR - Uma História da Roma Antiga (trad. P. Carvalho e Guerra \& R. Carvalho e Guerra a partir de $S P Q R$ - A History of Ancient Rome. Mary Becud Publications). Lisboa.

Chassignet, M. (1986), Caton. Les origines (fragments). 2ème tirage: 2002. Paris. Conway, R. S. \& Walters, C. F. (1955), Titi Liui Ab Vrbe Condita, Tom. I, Oxonii. Grimal, P. (2009), A civilização romana (trad. de Isabel St. Aubyn a partir de La Civilisation Romaine, Paris, 1984). Lisboa.

32 Albrecht 1997: 398. 
Hamblenne, P. (2000), “Des porcs engraissés en batterie, dans la Cisalpine?”, RBPh 78 1: 89-104.

Hooper, W. D. \& Ash, H. B. (1935, 2nd ed.), Marcus Porcius Cato. On agriculture; Marcus Terentius Varro. On agriculture, Cambridge (Mass.) - London.

Jordan, H. (1860), M. Catonis praeter librum de re rustica quae extant. Lipsiae.

Leão, D. \& Brandão, J. L. (2015), “2. As origens da Urbe e o período da Monarquia”, in J. L. Brandão \& F. Oliveira (coords.), História de Roma antiga, vol. I. Das origens à morte de César. Coimbra, 27-51.

Lindsay, W. M. (1913), De Verborum Significatione (Sexti Pompei Festi De Verborum Significatu Quae Supersunt cum Pauli Epitome). Lipsiae.

Malcovati, H. (1976, 4⿳⺈ ed.), Oratorum Romanorum fragmenta liberae rei publicae. Aug. Taurinorum.

Malson, L. (1988), As crianças selvagens: mito e realidade (trad. de C. Cidrais Rodrigues a partir de Les enfants sauvages: mythe et réalité. Union Générale d'Editions, 1964). Porto.

Montanelli, I. (2002), História de Roma. Da fundação à queda do Império (trad. de Ruy Oliveira a partir de Storia di Roma, Milão, 1997). Lisboa.

Nieto, J. (2006), Historia de Roma. Día a día en la Roma Antigua. Madrid.

Pereira, M. H. da Rocha (2010, 6ª ed.), Romana. Antologia da Cultura Latina. Lisboa.

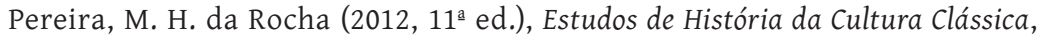
Cultura Grega. Lisboa.

Peter, H. (1914, $2^{\mathrm{a}}$ ed.), Historicorum Romanorum reliquiae, I. Lipsiae.

Ross, W. D. (1959). Aristotelis Ars Rhetorica (Repr. 1964). Oxford.

Todorov, Tzvetan (1977), Introdução à literatura fantástica (trad. de Maria Ondina Braga a partir de Introduction à la Littérature Fantastique, Paris, Seuil, 1970). Lisboa. 